\title{
Quantitative relationship between silica exposure and lung cancer mortality in German uranium miners, 1946-2003
}

\author{
M Sogl', , D Taeger², D Pallapies², T Brüning², F Dufey', M Schnelzer', K Straif ${ }^{3}$, L Walsh' and M Kreuzer' \\ 'Department of Radiation Protection and Health, BfS, Federal Office for Radiation Protection, Neuherberg 85764, Germany; ${ }^{2}$ Institute for Prevention and \\ Occupational Medicine of the German Social Accident Insurance, Institute of the Ruhr University Bochum (IPA), Bochum 44789, Germany; \\ ${ }^{3}$ IARC, International Agency for Research on Cancer, Lyon 69372, France
}

BACKGROUND: In 1996 and 2009, the International Agency for Research on Cancer classified silica as carcinogenic to humans. The exposure-response relationship between silica and lung cancer risk, however, is still debated. Data from the German uranium miner cohort study were used to further investigate this relationship.

METHODS: The cohort includes 58677 workers with individual information on occupational exposure to crystalline silica in $\mathrm{mg} \mathrm{m}^{-3}$-years and the potential confounders radon and arsenic based on a detailed job-exposure matrix. In the follow-up period 1946-2003, 2995 miners died from lung cancer. Internal Poisson regression with stratification by age and calendar year was used to estimate the excess relative risk (ERR) per dust-year. Several models including linear, linear quadratic and spline functions were applied. Detailed adjustment for cumulative radon and arsenic exposure was performed.

RESULTS: A piecewise linear spline function with a knot at $10 \mathrm{mg} \mathrm{m}^{-3}$-years provided the best model fit. After full adjustment for radon and arsenic no increase in risk $<10 \mathrm{mg} \mathrm{m}^{-3}$-years was observed. Fixing the parameter estimate of the ERR in this range at 0 provided the best model fit with an ERR of 0.06 I (95\% confidence interval: $0.039,0.083)>10 \mathrm{mg} \mathrm{m}^{-3}$-years.

CONCLUSION: The study confirms a positive exposure-response relationship between silica and lung cancer, particularly for high exposures.

British Journal of Cancer (2012) I 07, I| 88-| |94. doi:I0.1038/bjc.2012.374 www.bjcancer.com

Published online 28 August 2012

(C) 2012 Cancer Research UK

Keywords: epidemiology; silica; lung cancer; dose-response relationship; uranium miners

In 1996, the International Agency for Research on Cancer (IARC) classified crystalline silica, inhaled in the form of quartz from occupational sources, as carcinogenic to humans (group 1) with the lung as target organ (IARC, 1997). However, IARC noted a lack of extensive exposure-response data from epidemiological studies, differences in exposure metrics between the studies as well as inconsistencies in the exposure-response relationship across the studies. Since then, a number of individual studies (Ulm et al; 1999; Rice et al, 2001; Pukkala et al, 2005; Chen et al, 2007; Mundt et al, 2011; Vacek et al, 2011) on the relationship between occupational inhaled crystalline silica and lung cancer risk have been published, in addition to a series of meta- or pooled analyses (Brüske-Hohlfeld et al, 2000; Steenland et al, 2001; Kurihara and Wada, 2004; Lacasse et al, 2009; Erren et al, 2011) and reviews (Soutar et al, 2000; Pelucchi et al, 2006; Brown, 2009). In 2012 the IARC reconfirmed the classification of silica (IARC, 2012). However, there is still a debate on the shape of the exposureresponse relationship, especially in the low exposure range.

The two most recent and currently largest analyses addressing the shape of the relationship between cumulative silica exposure and lung cancer are a pooled analysis of 10 cohort studies by Steenland et al (2001) and a meta-analysis of 4 cohort and 6 casecontrol studies by Lacasse et al (2009). The meta-analysis showed a

*Correspondence: M Sogl; E-mail: msog|@bfs.de

Received 18 May 2012; revised 23 July 2012; accepted 26 July 2012; published online 28 August 2012 statistically significant increased risk $>1.8 \mathrm{mg} \mathrm{m}^{-3}$-years with a plateau $>6 \mathrm{mg} \mathrm{m}^{-3}$-years. The interpretation of these findings is limited by differences in the quality of silica exposure assessment reported in the original studies and heterogeneity across studies (Lacasse et al, 2009). The pooled analysis by Steenland et al (2001) included 65980 workers and 1079 lung cancer deaths over several industrial settings. There was a considerable heterogeneity between the various studies. An increase in risk with the natural logarithm of cumulative silica concentration was observed.

The German uranium miner cohort (Wismut cohort) study has a comparable size (nearly 60000 members) to the pooled analysis (Steenland et al, 2001); it includes a large number of lung cancer deaths $(n=2995)$ and provides a long follow-up with almost 2 million person-years. Individual information on occupational exposure to crystalline silica is available, which allows a detailed investigation of the shape of the dose-response relationship with particular focus on the low-dose range in a single study. Individual information on other known occupational carcinogens such as exposure to radon and arsenic dust is available and can be accounted for in the risk analyses. In addition, there is some information about smoking from a nested case-control study on lung cancer in the Wismut cohort (Schnelzer et al, 2010), which allows the evaluation of potential confounding by smoking. The aim of the present analyses is to investigate the shape of the exposure-response relationship between crystalline silica exposure and lung cancer mortality and the combined effect of silica and radon. 


\section{MATERIALS AND METHODS}

\section{Cohort definition and mortality follow-up}

The Wismut cohort has been described in detail (Grosche et al, 2006; Kreuzer et al, 2008, 2010a, b; Walsh et al, 2010a, b). In brief, the cohort includes 58987 males employed for at least 180 days between 1946 and 1989, selected as a random sample stratified by date of first employment, place of work and area of mining. Every cohort member contributes to the time at risk starting at the date of employment plus 180 days and ending at the earliest of date of death, date of loss to follow-up or the end of the follow-up period (31 December 2003). Information on the vital status of individuals was obtained from local registration offices, whereas death certificates were obtained from the responsible Public Health Administrations and the pathology archive of the Wismut company.

\section{Information on exposure to dust and radiation}

The silica and respirable fine dust content in the Wismut mines varied between time periods and mining regions and also between different mines within a given district, and even between regions within a specific mine (Dahmann et al, 2008). In the early period (1946-1954) the situation in mines was aggravated by poor industrial hygiene (i.e., dry drilling) and also by extremely low ventilation rates, i.e., air velocities $<0.1 \mathrm{~m} \mathrm{~s}^{-1}$ (Bauer, 1997; Dahmann et al, 2008). Thus, the dust exposures for the Wismut miners show high shift concentration averages for crystalline silica of well $>2 \mathrm{mg} \mathrm{m}^{-3}$ in many mines in the early times. After 1955 the situation improved continuously with the introduction of wet drilling and increasing mine ventilation rates up to about $0.3 \mathrm{~m} \mathrm{~s}^{-1}$. This resulted in a decrease of dust concentrations by $>97 \%$ (Bauer, 1997; Dahmann et al, 2008) as illustrated in Figure 1.

From 1960, systematic measurements of silica and fine dust concentrations performed by the Wismut company were available. Major efforts were undertaken to retrospectively quantify exposures to silica and fine dust before 1960, including reconstruction of historical workplaces and simulating ventilation conditions (Bauer, 1997; Dahmann et al, 2008). Using these estimates and measurements, a detailed job-exposure matrix (JEM) was developed (HVBG and BBG, 2005). This JEM provides annual exposure values for each calendar year, each place of work and job type (>900 different jobs and several mining facilities). Annual and cumulative exposures are given in units of dust-years that are $1 \mathrm{mg} \mathrm{m}^{-3}$ silica dust or fine dust over a time period of 220 shifts of $8 \mathrm{~h}$. Differences in the number of shifts and daily working hours in the different calendar years were accounted for. Figure 1 shows the mean annual exposure values for silica dust in the cohort. Silica dust is a proportion of the total measured respirable fine dust and therefore highly correlated with fine dust exposure $(r>0.95)$. Consequently, the variable respirable fine dust is excluded from all risk analyses.

Arsenic exposure occurred only in mines located in Saxony (Dahmann et al, 2008). The arsenic content in the deposit and data on dust exposure were used as proxy variables to estimate the arsenic exposure within the JEM because only a few measurements of arsenic levels in air were available. The cumulative exposure to arsenic dust is quantified in dust-years, where 1 dust-year equals an exposure of $1 \mu \mathrm{g} \mathrm{m}^{-3}$ over 220 shifts of $8 \mathrm{~h}$ (HVBG and BBG, 2005).

Information on exposures to ionising radiation is based on a separate JEM similar to that for dust. This JEM includes information on exposure to radon and its progeny in working level month (WLM), external gamma radiation in $\mathrm{mSv}$ and longlived radionuclides in $\mathrm{kBq} \mathrm{h} \mathrm{m}^{-3}$ (HVBG and BBG, 2005; Lehmann et al, 1998). Estimates for radon exposure were based on

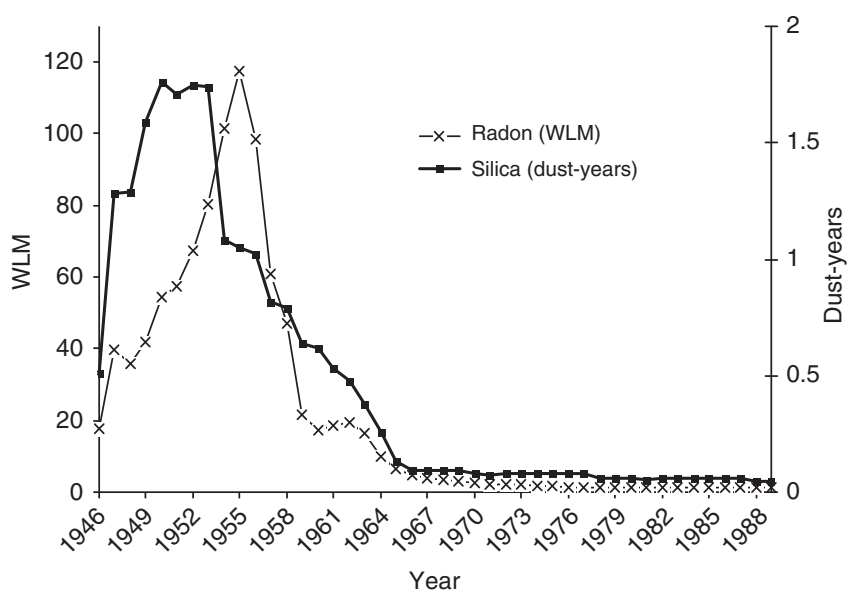

Figure I Mean annual exposure to silica dust in $\mathrm{mg} \mathrm{m}^{-3}$-years and radon and its progeny in WLM among exposed cohort members with respect to silica $(n=58677)$ and radon $(n=50468)$.

systematic measurements in the air from 1955 onwards, and on detailed expert rating in the years before (HVBG and BBG, 2005). A WL is defined as $1.3 \times 10^{3} \mathrm{MeV}$ of potential alpha energy per litre of air. One WLM corresponds to exposure to $1 \mathrm{WL}$ during 1 month, i.e., 170 working hours. The annual very high mean exposure values for radon and its progeny in the early years decreased after 1955 due to the introduction of ventilation measures (see Figure 1). Exposures to external gamma and longlived radionuclides are not considered in the risk analyses due to negligible doses to the lung compared with the radon progeny.

\section{Statistical methods}

Several RR models based on internal Poisson regression have been applied here to investigate the shape of the relationship between cumulative silica dust exposure and lung cancer mortality risk and its interaction with radon. The confidence intervals (CIs) were of the Wald-type at the $95 \%$ level. Age was stratified in 5-year groups and individual calendar year in 58 categories. Analogously to previous analyses on lung cancer (Grosche et al, 2006; Walsh et al, $2010 \mathrm{a}, \mathrm{b})$ a 5-year lag was used in calculating the cumulative exposures to allow for a latent period between exposure and death. Lag times of 0,10 and 15 years were also considered. Information on silica and arsenic dust was missing for 310 individuals of the cohort. Therefore, these individuals were excluded from all analyses leaving 58677 miners out of 58987 and 2995 out of 3016 lung cancer deaths. All models were fitted with the AMFIT module of the EPICURE software (Preston et al, 1998).

Main models for risk of lung cancer and silica In a first step, the RR of lung cancer death was estimated by a simple model with silica dust in categories. The following a priori defined cut-points were used for cumulative silica dust in $\mathrm{mg} \mathrm{m}^{-3}$-years $(0-0.5,0.5-$ $2,2-5,5-10,10-20,20-30$ and $30+$ ). In a second step, several excess relative risk (ERR) models with baseline stratification by age and calendar year were used. If $r(a, y$, sil, rn, ars $)$ is the specific lung cancer mortality rate for age, $a$; year, $y$; silica, sil; radon, rn; arsenic, ars; and $r_{0}(a, y)=r(a, y, 0,0,0)$ is the baseline disease rate for non-exposed individuals, then

$$
r(a, y, \text { sil, rn, ars })=r_{0}(a, y) \cdot\{1+\operatorname{ERR}(\text { sil, rn, ars })\} .
$$

Here, ERR is the excess RR for which several different functions of sil were tested: 
1. A linear function $\operatorname{ERR}(\mathrm{sil})=\beta \cdot$ sil, where sil is the total cumulative exposure to silica dust in $\mathrm{mg} \mathrm{m}^{-3}$-years.

2. A piecewise linear spline function with one knot.

$$
\operatorname{ERR}(\text { sil })=\left\{\begin{array}{cc}
\beta_{1} \cdot \text { sil } & \text { sil } \leqslant \operatorname{sil}_{k} \\
\beta_{1} \cdot \text { sil }+\beta_{2} \cdot\left(\operatorname{sil}-\operatorname{sil}_{\mathrm{k}}\right) & \text { sil }>\operatorname{sil}_{\mathrm{k}}
\end{array}\right.
$$

Different locations of the knots $\operatorname{sil}_{\mathrm{k}} \in\{5,7,8,9,10,11,12,15\}$ in $\mathrm{mg} \mathrm{m}^{-3}$-years were tested. A model in which $\beta_{1}$ was fixed at zero was also fitted.

3. Quadratic as well as linear-quadratic functions of cumulative silica exposure.

To adjust for potential confounding in the models above, the cumulative radon and arsenic exposures were first included as continuous variables in a linear way. Previous analyses on the relationship between lung cancer and cumulative radon exposure in the Wismut cohort provided evidence for a model that is linear in radon exposure with the exponential effect modifiers age at median exposure (or attained age), time since median exposure and radon exposure rate (Walsh et al, 2010a, b). Therefore, these three exponential effect modifiers of radon exposure were then additionally included to achieve better adjustment for the major confounder radon. The preferred models were identified by applying model techniques for nested models, i.e., the likelihood ratio test (see Walsh, 2007 for an explanation). Adjustment for confounders was performed in an additive and in a multiplicative way. As the additive model provided a better fit, only these results are shown.

Effect modification Effect modification by age, time and exposure rate was present in the radon-induced lung cancer risk. These factors may also modify the effect of the silica-induced lung cancer risk. Therefore, all possible combinations of effect modification on silica and radon were tested. The effect modifiers were calculated in analogy to the calculations for radon (Walsh et al, 2010b). The aim was to obtain the best suited and most parsimonious model to describe the combined effect of silica and radon.

Quantification of the combined effect of silica and radon In a first step, the combined effect of silica dust and radon on the risk of lung cancer death was described by simple categorical analyses with combinations of radon $(<50,50-1000$ and $>1000$ WLM $)$ and silica dust $\left(<10,10-20,20-30\right.$ and $30+\mathrm{mg} \mathrm{m}^{-3}$-years $)$ without consideration of arsenic and risk effect modifiers. To gain more insight into the form (additive or multiplicative) of the interaction between silica and radon, a geometric mixture model that is piecewise linear in silica (with a knot at $10 \mathrm{mg} \mathrm{m}^{-3}$-years) and linear in radon with effect modifiers for silica and radon and adjustment for arsenic, as described above, was fitted: $1+\mathrm{ERR}_{\text {mix }}=\left(1+\mathrm{ERR}_{\text {mult }}\right)^{\lambda}\left(1+\mathrm{ERR}_{\mathrm{add}}\right)^{1-\lambda}$

The mixing parameter $\lambda(0 \leqslant \lambda \leqslant 1)$ was first set to 0.0 (additive) and was then enhanced up to 1.0 (multiplicative) in 0.1-length steps.

\section{RESULTS}

Among the 58677 cohort members, 20748 died overall between 1946 and 2003 while 2995 died from lung cancer. The cause of death was available for $93.6 \%$ of the miners. In all, $4.7 \%$ were lost to follow-up. The cohort members contributed 1984687 personyears with an average follow-up period of 34 years, and the mean duration of employment was 14 years. All cohort members were exposed to silica dust at some time, because silica occurred not only underground but also in appreciably lower concentrations at the surface (Table 1).

In Table 2 the risk of lung cancer death in relation to cumulative silica dust exposure is given. A positive trend could be observed.
Table I Exposures of the Wismut cohort, 1946-2003

\begin{tabular}{lcccccc}
\hline Cumulative exposure to & Exposed (\%) & Mean & Median & Max & s.d. \\
\hline Silica (mg m ${ }^{-3}$-years) & 100 & 5.9 & 1.8 & 56 & 8.0 \\
Radon (WLM) & 86 & 280 & 33 & 3224 & 445 \\
Arsenic ( $\mu \mathrm{g} \mathrm{m}^{-3}$-years) & 31 & 121 & 67 & 1417 & 145 \\
\hline
\end{tabular}

Abbreviation: WLM = working level months.

Without adjustment for radon and arsenic a statistically significant increased $\mathrm{RR}$, compared with the reference category of $0-0.5 \mathrm{mg} \mathrm{m}^{-3}$-years was present in all categories except for the category $0.5-2 \mathrm{mg} \mathrm{m}^{-3}$-years (see also Figure $2 \mathrm{~A}$ ). After adjustment for the major confounder radon, all estimates decreased markedly, but remained statistically significant in the exposure categories $10-20,20-30$ and $30-56 \mathrm{mg} \mathrm{m}^{-3}$-years. Additional adjustment for cumulative arsenic exposure led to a significant improvement of the model fit quality, but only to a small decrease of the RR (Table 2). More detailed adjustment for radon including the effect modifiers age at median exposure, time since median exposure and radon exposure rate, led to a further decrease of the silica-induced risk, showing a statistically significant increased risk only in the categories $20-30$ and $30-56 \mathrm{mg} \mathrm{m}^{-3}$-years.

As the categorical analyses indicated a non-linear exposure response relationship (Figure 2A), two-line spline models with different knots were applied and compared by model selection procedures (Walsh, 2007). Models with silica dust as linear spline with one knot at 7, 8, 9 and $10 \mathrm{mg} \mathrm{m}^{-3}$-years yielded in statistically better fits compared with the pure linear model. After adjustment for radon and arsenic a spline model with a knot at $10 \mathrm{mg} \mathrm{m}^{-3}$ -years provided the best fit. Table 3 provides information on the risk estimates for the model parameters $\beta_{1}$ and $\beta_{2}$ and the corresponding RRs at 5 and $15 \mathrm{mg} \mathrm{m}^{-3}$-years based on the spline model, with a knot at $10 \mathrm{mg} \mathrm{m}^{-3}$-years. Without adjustment for radon and arsenic, the RR was $1.34(95 \%$ CI: $1.20 ; 1.47)$ at $5 \mathrm{mg} \mathrm{m}^{-3}$-years and 2.44 (95\% CI: $\left.1.96 ; 2.61\right)$ at $15 \mathrm{mg} \mathrm{m}^{-3}$-years compared with 0 dust-years. The RRs decreased after simple adjustment for radon and arsenic. After more detailed adjustment for radon, i.e., inclusion of the three exponential effect modifiers the silica risk estimates further decreased to 0.97 (95\% CI: 0.86 ; $1.08)$ at $5 \mathrm{mg} \mathrm{m}^{-3}$-years and 1.24 (95\% CI: $\left.0.98 ; 1.49\right)$ at $15 \mathrm{mg} \mathrm{m}^{-3}$-years, but yielded significant RRs for cumulative exposures $>16 \mathrm{mg} \mathrm{m}^{-3}$-years (Figure $2 \mathrm{~B}$ ). As $\beta_{1}$ decreased to $-0.006(-0.028 ; 0.015)$ after full adjustment, a model in which $\beta_{1}$ was fixed at zero was fitted additionally. The preferred model was achieved after detailed adjustment for the confounder radon (with effect modifiers) and arsenic and $\beta_{1}$ fixed at zero between 0 and $10 \mathrm{mg} \mathrm{m}^{-3}$-years. Quadratic and linear quadratic models of cumulative silica exposure did not result in an improvement in goodness of fit.

The best suited and most parsimonious model, to describe both effects of silica and radon and their corresponding time- and doserate-related effect modifiers, was piece-wise linear in cumulative silica dust with one knot at $10 \mathrm{mg} \mathrm{m}^{-3}$-years, with the initial slope fixed at 0 below $10 \mathrm{mg} \mathrm{m}^{-3}$-years including attained age as exponential effect modifier. Table 3 shows that the preferred model had a deviance of 30592.5 and one parameter less than the model with the optimised initial slope (deviance $=30592.3$ ). It was linear in radon with exponential effect modifiers that depend on time since median exposure and radon-exposure rate. The silicainduced lung cancer risk decreases with increasing attained age (Table 3).

In Table 4 the results of the categorical analyses on the combined effect of radon and silica are shown. There was an increase of the RR of silica (see increase in columns), and an increase of the RR of radon (see rows). The risk in the highest silica and radon exposure category $\left(>30 \mathrm{mg} \mathrm{m}^{-3}\right.$-years and 
Table 2 Risk of death from lung cancer by cumulative silica dust exposure in $\mathrm{mg} \mathrm{m}^{-3}$-years by categories, 1946-2003

\begin{tabular}{|c|c|c|c|c|c|c|c|}
\hline Silica dust in $\mathrm{mg} \mathrm{m}^{-3}$-years & Mean & $\begin{array}{l}\text { Person- } \\
\text { years }\end{array}$ & $\begin{array}{l}\text { \# of } \\
\text { cases }\end{array}$ & $\begin{array}{l}\text { RR } 95 \% \text { Cl } \\
\text { unadjusted }\end{array}$ & $\begin{array}{l}\text { RR } 95 \% \mathrm{Cl} \\
\text { adjusted for radon }\end{array}$ & $\begin{array}{c}\text { RR } 95 \% \text { CI } \\
\text { adjusted for } \\
\text { radon, arsenic }\end{array}$ & $\begin{array}{l}\text { RR } 95 \% \mathrm{Cl} \text { adjusted } \\
\text { for radon, arsenic } \\
\text { with effect modifiers }\end{array}$ \\
\hline $0-0.5$ & 0.1 & 681780 & 137 & I.00 Reference & I.00 Reference & I.00 Reference & I.00 Reference \\
\hline $0.5-2$ & । & 394559 & 283 & $1.12(0.89-1.35)$ & $1.09(0.86-1.31)$ & $1.08(0.86-|.3|)$ & $0.95(0.77-1.12)$ \\
\hline $2-5$ & 3 & 274523 & 356 & $1.26(1.00-1.51)$ & $1.15(0.91-1.38)$ & $1.13(0.89-1.37)$ & $0.96(0.78-1.13)$ \\
\hline $5-10$ & 7 & 238032 & 430 & $1.38(1.10-1.66)$ & $1.07(0.83-1.30)$ & $1.05(0.81-1.28)$ & $0.86(0.67-1.04)$ \\
\hline $10-20$ & 14 & $264 \mid 40$ & 936 & $2.45(1.98-2.92)$ & $1.53(1.19-1.88)$ & $1.47(1.13-1.81)$ & I.I $4(0.87-1.40)$ \\
\hline $20-30$ & 24 & 108502 & 664 & $3.76(3.02-4.49)$ & $2.19(1.64-2.75)$ & $2.05(|.5|-2.60)$ & $|.5|(1.08-1.94)$ \\
\hline $30-56$ & 34 & $23|5|$ & 189 & $4.71(3.62-5.80)$ & $2.91(1.96-3.83)$ & $2.79(1.87-3.70)$ & $2.02(1.28-2.75)$ \\
\hline Total & 5.9 & | 984687 & 2995 & & & & \\
\hline
\end{tabular}

Abbreviations: Adj. = adjusted; $\mathrm{Cl}=$ confidence interval; $\mathrm{RR}=$ relative risk. $\mathrm{RR}$, baseline stratified on age in 5 -year groups and individual calendar year in 58 categories. $\mathrm{RR}$ adj. for radon (last-but-two column), for radon and arsenic (next-to-last column) and for radon with exponential inclusion of the effect modifiers age at median exposure, time since median exposure and radon exposure rate and arsenic (last column) as continuous variables in an additive way.
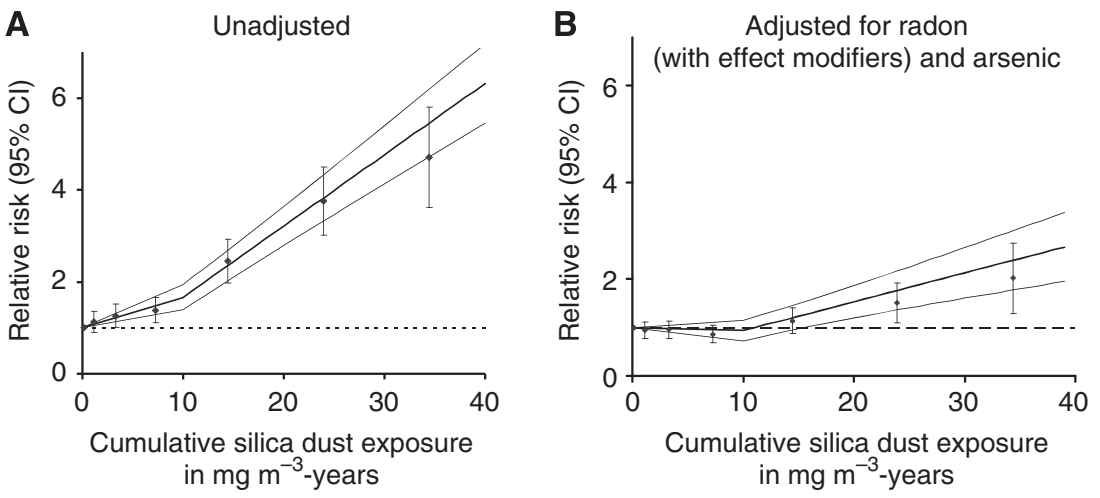

Figure 2 RR of death from lung cancer $(n=2995)$ in relation to cumulative silica dust without adjustment $(\mathbf{A})$ and with additive adjustment for radon (with the effect modifiers age at median exposure, time since median exposure and radon exposure rate) and arsenic (B). Categorical analysis (0-0.5, 0.5-2, 2-5, 5-10, 10-20, 20-30 and 30+) and linear spline model (bold line) with 95\% confidence limits (fine lines).

$>1000$ WLM) is 4.6-fold (95\% CI: 3.7-5.4) higher compared with the risk in the reference category $\left(<10 \mathrm{mg} \mathrm{m}^{-3}\right.$-years and $<50$ WLM). With the geometric mixture model, the form of the interaction between silica and radon was further investigated. The purely additive model provided a statistically significant better fit compared with the multiplicative model. These results indicate that the effects of silica and radon exposure are more likely to be additive rather than multiplicative.

\section{DISCUSSION}

The analysis of the Wismut uranium miner cohort study showed a statistically significant positive exposure-response relationship between silica and lung cancer for high cumulative silica exposures. Analyses on the combined effects of radon and silica provided evidence for a more additive rather than multiplicative relationship of both effects.

In contrast to other studies, beside silica a strong second risk factor - radon - was present in the cohort. Both variables correlate over time $(r=0.79)$ with high exposures in the very early years and low exposures later (Figure 1). Thus, the major challenge in the statistical analyses was to fully account for this strong confounder. The large size of the cohort and the detailed information on both risk factors enabled this adjustment. Owing to the relatively high correlation of radon and dust over time and the fact that radon is a stronger risk factor than silica, it cannot be ruled out that adjustment for radon including the three effect modifiers may have led to some over adjustment. Therefore, a small increase in risk even in the range $<10 \mathrm{mg} \mathrm{m}^{-3}$-years cannot be ruled out.
Arsenic exposure was high in the early years and decreased later, however, the correlation with silica was low $(r=0.46)$, and arsenic itself a weak risk factor. The decrease in the silica-induced lung cancer risk was small after adjustment for arsenic. Restriction of the cohort data to individuals without any arsenic exposure ( $n=40753$ ) showed a very similar exposure-response pattern (RR at $15 \mathrm{mg} \mathrm{m}^{-3}$-years $=1.35$; $95 \% \mathrm{CI}: 1.17-1.53$ ) compared with the non-restricted data $(\mathrm{RR}=1.31 ; 95 \% \mathrm{CI}: 1.20-1.42)$ for the fully adjusted model.

The preferred model indicated that attained age modifies the silica-induced risk. With increasing attained age, the risk for silicainduced lung cancer decreases. Again, owing to the high timely correlation of both factors and the fact that radon is a stronger risk factor, it cannot be resolved whether there could be other modifying factors for the silica-induced lung cancer risk.

\section{Limitations}

A possible limitation of this study could be misclassification of the silica exposure in the early years from 1946 to 1960 when no measurements for silica were available. A very detailed expert assessment had been performed with simulated, remodelled historical exposure settings using historic equipments, model calculations and expert rating (Dahmann et al, 2008). Thus, misclassification, if present, should be small.

A further limitation is the lack of individual information on the potential confounder smoking. In a nested case-control study on lung cancer some information on smoking based on data from the medical archives or from relatives was obtained for 439 cases and 550 controls (Schnelzer et al, 2010). No statistically significant 
Table 3 Risk of lung cancer death by cumulative silica exposure in a linear spline model with one knot at $10 \mathrm{mg} \mathrm{m}^{-3}$-years, $1946-2003$

\begin{tabular}{|c|c|c|c|c|c|}
\hline Model & $\beta_{1}{ }^{a} 95 \% \mathrm{Cl}$ & $\beta_{2}{ }^{b} 95 \% \mathrm{Cl}$ & Deviance & $\begin{array}{c}\mathbf{R R}^{\mathrm{c}} 95 \% \mathrm{Cl} \\
5 \mathrm{mg} \mathrm{m}^{-3} \text {-years }\end{array}$ & $\begin{array}{c}\text { RR } 95 \% \mathrm{Cl} \\
\text { I5 } \mathrm{mg} \mathrm{m}^{-3} \text {-years }\end{array}$ \\
\hline Unadjusted & $0.067(0.039 ; 0.094)$ & $0.088(0.058 ; 0.119)$ & 30768.1 & $1.34(1.20 ; 1.47)$ & $2.44(1.96 ; 2.61)$ \\
\hline Adjusted for radon and arsenic ${ }^{e}$ & $0.012(-0.011 ; 0.035)$ & $0.068(0.038 ; 0.098)$ & 30688.2 & $1.06(0.95 ; 1.18)$ & $1.52(1.24 ; 1.79)$ \\
\hline \multirow{3}{*}{$\begin{array}{l}\text { Adjusted for radon (with exponential } \\
\text { effect modifiers }{ }^{\circ} \text { ) and arsenic } \\
\text { 0-year lag } \\
\text { 10-year lag } \\
\text { 15-year lag }\end{array}$} & $-0.006(-0.028 ; 0.015)$ & $0.066(0.038 ; 0.094)$ & 30604.2 & $0.97(0.86 ; 1.08)$ & $1.24(0.98 ; 1.49)$ \\
\hline & $0.000\left(\right.$ fixed $\left.^{g}\right)$ & $0.061(0.039 ; 0.083)$ & 30604.5 & 1.00 (fixed) & $1.31(1.20 ; 1.42)$ \\
\hline & 0.000 (fixed) & $0.062(0.039 ; 0.085)$ & & 1.00 (fixed) & $1.31(1.20 ; 1.43)$ \\
\hline \multirow{4}{*}{$\begin{array}{l}\text { Silica with exponential effect modifier } \\
\text { attained age (centred at } 64 \text { years) } \\
\text { adjusted for radon (with exponential modifiers }{ }^{h} \text { ) and arsenic } \\
50 \text { years attained age } \\
60 \text { years } \\
70 \text { years } \\
80 \text { years }\end{array}$} & 0.000 (fixed) & $0.073(0.046 ; 0.100)$ & 30592.5 & 1.00 (fixed) & $1.37(1.23 ; 1.50)$ \\
\hline & $0.002(-0.014 ; 0.018)$ & $0.073(0.043 ; 0.100)$ & 30592.3 & I.0। $(0.93 ; 1.09)$ & $1.39(1.16 ; 1.63)$ \\
\hline & $0.007(-0.040 ; 0.057)$ & $0.223(0.142 ; 0.322)$ & 30592.3 & $1.04(0.80 ; 1.29)$ & $2.21(1.43 ; 3.02)$ \\
\hline & $0.003(-0.019 ; 0.025)$ & $0.105(0.066 ; 0.134)$ & 30592.3 & $1.15(0.90 ; 1.13)$ & $1.55(1.30 ; 1.84)$ \\
\hline
\end{tabular}

Abbreviations: $\mathrm{Cl}=$ confidence interval; $\mathrm{ERR}=$ excess relative risk. ${ }^{\mathrm{a}, \mathrm{b}} \beta_{\mathrm{l}}$ and $\beta_{2}$ describe the $\mathrm{ERR}$ in the following way, sil ${ }_{\mathrm{k}}=10$ :

$\operatorname{ERR}(\operatorname{sil})=\left\{\begin{array}{cc}\beta_{1} \cdot \text { sil } & \text { sil } \leqslant \operatorname{sil}_{k} \\ \beta_{1} \cdot \operatorname{sil}+\beta_{2} \cdot\left(\operatorname{sil}-\operatorname{sil}_{k}\right) & \text { sil }>\operatorname{sil}_{k}\end{array}\right.$

${ }^{\mathrm{c}}$ Relative risk with $95 \% \mathrm{Cl}$ for a cumulative exposure of $5 \mathrm{mg} \mathrm{m}^{-3}$-years compared with $0 .{ }^{\mathrm{d}}$ Adjusted for cumulative radon exposure in a linear way. ${ }^{\mathrm{e}}$ Adjusted for cumulative radon and arsenic exposure in a linear way. ${ }^{f}$ Exponential effect modifiers age at median exposure, time since median exposure and radon exposure rate. ${ }^{g}$ Parameter $\beta$, is fixed at 0. hexponential effect modifiers, time since median exposure and radon exposure rate.

Table 4 Combined effect of cumulative exposure to silica and radon on the risk of death from lung cancer, Wismut cohort, 1946-2003

\begin{tabular}{|c|c|c|c|c|c|c|c|}
\hline Silica dust $\mathrm{mg} \mathrm{m}^{-3}$-years & \multicolumn{7}{|c|}{ Radon } \\
\hline$<10$ & 609 & I.0 Reference & 585 & $1.52(1.34-1.69)$ & 12 & $1.95(0.83-3.07)$ & 1206 \\
\hline $10-20$ & 54 & $1.10(0.79-1.41)$ & 663 & $2.45(2.17-2.73)$ & 219 & $3.11(2.62-3.61)$ & 936 \\
\hline $20-30$ & 6 & $1.33(0.26-2.4 I)$ & 238 & $3.11(2.63-3.60)$ & 420 & $4.29(3.64-4.74)$ & 664 \\
\hline Total & 669 & & 1528 & & 798 & & 2995 \\
\hline
\end{tabular}

Abbreviations: $\mathrm{Cl}=$ confidence interval; $\mathrm{RR}=$ relative risk; $\mathrm{WLM}=$ working level month.

trend in the proportion of smokers with increasing silica exposure for both lung cancer cases and controls was observed (two-sided test for trend: $P=0.31$ for cases, $P=0.52$ for controls; Figure 3). Pukkala et al (2005) observed no increased risk of lung cancer in their preferred model in the category $1.0-9.9 \mathrm{mg} \mathrm{m}^{-3}$-years $(\mathrm{RR}=0.97 ; 95 \% \mathrm{CI}: 0.91-1.03)$ compared with $0 \mathrm{mg} \mathrm{m}^{-3}$-years and a statistically significant risk $>10 \mathrm{mg} \mathrm{m}^{-3}$-years $(\mathrm{RR}=1.42 ; 95 \%$ CI: 1.20-1.70) after adjustment for smoking on aggregate level. This is similar to results given in Table 2 and therefore possibly further evidence that smoking is not a major confounder in this study. However, residual confounding by smoking cannot be fully excluded, because data on duration and amount of smoking are incomplete.

Silicosis is debated as possible effect modifier of the silicainduced lung cancer risk (Hnizdo et al, 1997; Ulm et al, 1999; Soutar et al, 2000; Pelucchi et al, 2006; Taeger et al, 2008; Brown, 2009; Erren et al, 2011) and the carcinogenic role of silica in the absence of silicosis is still debated. There is consistent evidence of an increased lung cancer risk among silicotics, whereas studies restricted to non-silicotics or those with 'unknown silicotic status' mainly show no increased risk of lung cancer. Many studies, however, suffer from insufficient information on silicosis status (e.g., Steenland et al, 2001; Attfield and Costello, 2004; Lacasse

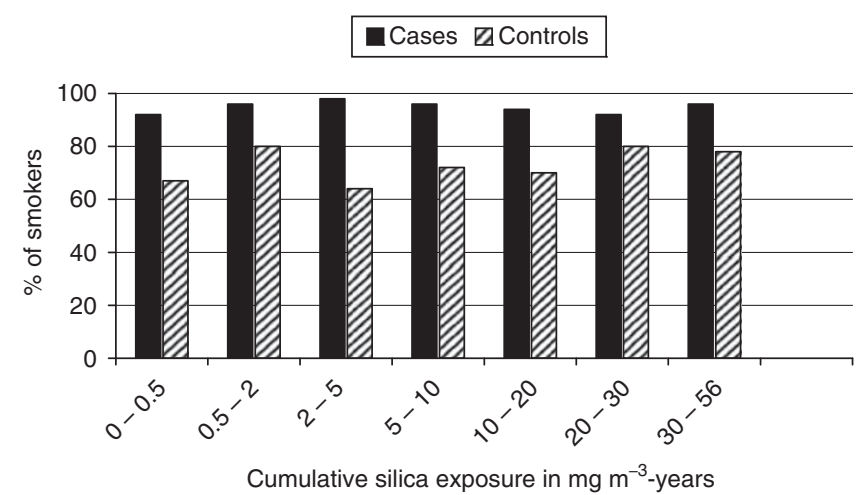

Figure 3 Percentages of smokers within cases $(n=439)$ and controls $(n=550)$ from a nested case-control study (Schnelzer et al, 20 l0) on lung cancer among the Wismut miners. A smoker is defined as a person who ever smoked in the last 20 years before death (for cases) or the reference case's death (for controls).

et al, 2009) or missing quantitative data on silica exposure. In the Wismut cohort selective data on silicosis are available. For a total of 3645 cohort members silicosis was noted on the death 
Table 5 Risk of death from lung cancer by cumulative silica dust exposure in $\mathrm{mg} \mathrm{m}^{-3}$-years by categories after exclusion of known silicotics, $1946-2003$

Cohort excluding known silicotics

\begin{tabular}{|c|c|c|c|c|c|c|}
\hline $\begin{array}{l}\text { Silica dust in } \\
\mathrm{mg} \mathrm{m}^{-3} \text {-years }\end{array}$ & $\begin{array}{l}\text { Person- } \\
\text { years }\end{array}$ & $\begin{array}{c}\text { \# of lung } \\
\text { cancer deaths }\end{array}$ & $\begin{array}{l}\text { RR } 95 \% \mathrm{Cl} \text { adjusted } \\
\text { for radon and arsenic }\end{array}$ & $\begin{array}{l}\mathrm{RR} 95 \% \mathrm{Cl} \text { adjusted for } \\
\text { radon and arsenic with } \\
\text { effect modifiers }\end{array}$ & $\begin{array}{l}\text { Person- } \\
\text { years }\end{array}$ & $\begin{array}{c}\text { \# of lung } \\
\text { cancer deaths }\end{array}$ \\
\hline $0-0.5$ & 665199 & 137 & I.00 Reference & I.00 Reference & 16497 & 0 \\
\hline $0.5-2$ & 390539 & 276 & $1.12(0.86-\mid .31)$ & $0.98(0.79-1.18)$ & 4019 & 7 \\
\hline $2-5$ & $267|6|$ & 333 & $1.12(0.88-1.36)$ & $0.97(0.78-1.17)$ & 7361 & 23 \\
\hline $5-10$ & 223766 & 379 & $1.06(0.82-1.30)$ & $0.88(0.69-1.07)$ & $14 \mid 46$ & 51 \\
\hline $10-20$ & 219248 & 675 & $1.44(1.10-1.78)$ & $1.16(0.89-1.43)$ & 44600 & 261 \\
\hline $20-30$ & 66313 & 308 & $1.64(1.13-2.15)$ & $1.31(0.92-1.70)$ & 41874 & 356 \\
\hline $30-56$ & 11864 & 68 & $1.87(0.98-2.77)$ & $1.31(0.63-1.99)$ & $1 \mid 192$ & 121 \\
\hline Total & | 844090 & 2176 & & & 139692 & 819 \\
\hline
\end{tabular}

Abbreviations: $\mathrm{Cl}=$ confidence interval; $\mathrm{RR}=$ relative risk. $\mathrm{RR}$ adjusted for radon and arsenic (forth column) and for radon with exponential inclusion of the effect modifiers age at median exposure, time since median exposure and radon exposure rate and arsenic (fifth column) as continuous variables in an additive way

certificates, the autopsy protocols or the protocols of the medical archive of the Wismut company. It is unclear how valid this information is. For the remaining 55032 cohort members, the silicosis status is unknown. Categorical risk analyses excluding the 3645, known' silicotics (Table 5) show elevated RR's in the silica exposure categories $>10 \mathrm{mg} \mathrm{m}^{-3}$-years after full adjustment. The corresponding estimate for the parameter $\beta_{2}$ (>10 $\mathrm{mg} \mathrm{m}^{-3}$-years) was $0.034(95 \%$ CI: $0.013 ; 0.055)$, which is appreciably lower compared with that in the full data set $\left(\beta_{2}=0.061 ; 95 \%\right.$ CI: 0.039 ; $0.083)$. It is unclear whether this excess is real or due to residual confounding (misclassified non-silicotics). Moreover, the statistical power is reduced, because the majority of highly radon- and silica-exposed cohort members were excluded as silicotics.

\section{Comparison with other epidemiological studies}

The increase in risk with increasing exposure in this study is consistent with other studies (Checkoway et al, 1997; Brüske-Hohlfeld et al, 2000; Rice et al, 2001; Steenland et al, 2001; Pukkala et al, 2005; Lacasse et al, 2009). On the other hand, a few single studies concluded that there was no evidence that crystalline silica acts as a risk factor for lung cancer (Steenland and Brown, 1995; Ulm et al, 1999; Graham et al, 2004; Chen et al, 2007; Mundt et al, 2011; Vacek et al, 2011). Exposures in some of these studies (Graham et al, 2004; Vacek et al, 2011) or parts of the study (Chen et al, 2007) have been quite low or subjects with silicosis had been omitted (Ulm et al, 1999).

Steenland et al (2001) pooled 10 cohort studies from a variety of industries and countries. The pooled study included 65980 workers and 1079 lung cancer deaths. The logarithm of cumulative exposure with a 15-year lag showed a statistically significant positive trend with lung cancer risk. Categorical analyses by quintiles of cumulative silica exposure resulted in odds ratios of 1.0, 1.0 (95\% CI, 0.85-1.3), 1.3 (95\% CI, 1.1-1.7), 1.5 (95\% CI, $1.2-$ $1.9)$ and $1.6(95 \% \mathrm{CI}, 1.3-2.1)$ for cumulative silica exposure of $<0.4,0.4-2.0,2.0-5.4,5.4-12.8$ and $>12.8 \mathrm{mg} \mathrm{m}^{-3}$-years, respectively. The risks for high exposures are approximately comparable to the present results, however, slightly shifted with a RR in this study of $1.51 \quad(95 \%$ CI: 1.08-1.94) in the category $20-30 \mathrm{mg} \mathrm{m}^{-3}$-years. The odds ratios of the lower exposure categories are appreciably higher compared with the fully adjusted risks presented here, but the CIs overlap in both studies. No adjustment for smoking and other confounders was made. Furthermore, there was a considerable heterogeneity between the various studies in this pooled analysis.

The meta-analysis of Lacasse et al (2009) included four cohort studies and six case-control studies having quantitative measurements of crystalline silica exposure and adjustment for smoking. An increase in risk of lung cancer was observed with increasing cumulative silica exposure. Differences in the quality of silica exposure assessment of the original studies and significant heterogeneity across the studies limit its interpretation.

In conclusion, results indicate an elevated lung cancer risk at higher cumulative silica exposures. No increase in risk in the range $<10 \mathrm{mg} \mathrm{m}^{-3}$-years was found, but a small increase cannot be ruled out. It is unclear whether these results can be applied to other industrial settings than uranium mining. In this study, even in the absence of known silicotics some increase in the silicainduced lung cancer risk was observed, however, this result has to be treated with caution due to possibly incomplete data on silicotics. Overall, the findings of this study support the evaluation of the IARC to classify silica as carcinogenic to humans with the lung as target organ $(1997,2012)$. The extension of the follow-up period to the end of 2008 will allow more detailed analyses of the low exposure range with alternative models.

\section{ACKNOWLEDGEMENTS}

We thank the Institution of Dangerous Materials (Institut für Gefahrstoffe) in Bochum (Professor Bauer, Dr Stoyke, Dr Dahmann) for developing the JEM on dust and arsenic, the Miners' Occupational Compensation Board (Bergbau-Berufsgenossenschaften) in Gera (Dr Lehmann) for developing the JEM for radiation and the German Statutory Accident Insurance (Deutsche Gesetzliche Unfallversicherung) for providing relevant data on miners. We also thank Dr Annemarie Tschense from the BfS for data collection. This work was supported by the Federal Ministry of Education and Research (BMBF), Germany (Competence Network Radiation Research, project 'Individual Susceptibility and Genomic Instability', grant number NUK007C).

\section{REFERENCES}

Attfield MD, Costello J (2004) Quantitative exposure-response for silica dust and lung cancer in Vermont granite workers. Am J Ind Med 45: $129-138$
Bauer H-D (1997) Staubbelastungen in untertägigen Betrieben der ehemaligen Wismut während der Frühphase der Uranerzgewinnung nach dem 2. Weltkrieg. Gefahrstoffe - Reinhaltung der Luft 57: 349-354 
Brown T (2009) Silica exposure, smoking, silicosis and lung cancer complex interactions. Occup Med 59: 89-95

Brüske-Hohlfeld I, Möhner M, Pohlabeln H, Ahrens W, Bolm-Audorff U, Kreienbrock L, Kreuzer M, Jahn I, Wichmann H-E, Jöckel K-H (2000) Occupational lung cancer risk for men in Germany: results from a pooled case-control study. Am J Epidemiol 151: 384-395

Checkoway H, Heyer NJ, Seixas NS, Welp E, Demers P, Hughes J, Weill H (1997) Dose-response associations of silica with non-malignant respiratory disease and lung cancer mortality in the diatomaceous earth industry. Am J Epidemiol 145: 680-688

Chen W, Bochmann F, Sun Y (2007) Effects of work related confounders on the association between silica exposure and lung cancer: a nested casecontrol study among Chinese miners and pottery workers. Int Arch Occup Environ Health 80: 320-326

Dahmann D, Bauer HD, Stoyke G (2008) Retrospective exposure assessment for respirable and inhalable dust, crystalline silica and arsenic in the former German uranium mines of SAG/SDAG Wismut. Int Arch Occup Environ Health 81: 949-958

Erren TC, Morfeld P, Glende C, Piekarski C, Cocco P (2011) Meta-analyses of published epidemiological studies, 1979-2006, point to open causal questions in silica-silicosis-lung cancer research. Med Lav 102(4): 321-335

Graham WG, Costello J, Vacek PM (2004) Vermont granite mortality study: an update with an emphasis on lung cancer. J Occup Eviron Med 46: 459-466

Grosche B, Kreuzer M, Kreisheimer M, Schnelzer M, Tschense A (2006) Lung cancer risk among German male uranium miners: a cohort study, 1946-1998. Br J Cancer 95: 1280-1287

Hnizdo E, Murray J, Klempman S (1997) Lung cancer in relation to exposure to silica dust, silicosis and uranium production in South African gold miners. Thorax 52: 271-275

HVBG and BBG (2005) Belastung durch ionisierende Strahlung, Staub und Arsen im Uranerzbergbau der ehemaligen DDR (Version 08/2005). Bergbau BG (BBG): St. Augustin, Hauptverband der gewerblichen Berufsgenossenschaften (HVBG) (CD-Rom): Gera

International Agency for Research on Cancer (1997) IARC Monographs on the Evaluation of Carcinogenic Risks to Humans, Vol 68, Silica, Some Silicates, Coal Dust and Para-Aramid Fibrils. International Agency for Research on Cancer: Lyon

International Agency for Research on Cancer (2012) IARC Monographs on the Evaluation of Carcinogenic Risks to Humans, Vol 100C, Arsenic, Metals, Fibres, and Dust. International Agency for Research on Cancer: Lyon

Kreuzer M, Grosche B, Schnelzer M, Tschense A, Dufey F, Walsh L (2010b) Radon and risk of death from cancer and cardiovascular diseases in the German uranium miners cohort study, 1946-2003. Radiat Environ Biophys 49: 177-185

Kreuzer M, Schnelzer M, Tschense A, Walsh L, Grosche B (2010a) Cohort profile: the German uranium miners cohort study (Wismut cohort), 1946-2003. Int J Epidemiol 39: 980-987

Kreuzer M, Walsh L, Schnelzer M, Tschense A, Grosche B (2008) Radon and risk of extrapulmonary cancers: results of the German uranium miners cohort study, 1960-2003. Br J Cancer 99: 1946-1953

Kurihara N, Wada O (2004) Silicosis and smoking strongly increase lung cancer risk in silica-exposed workers. Ind Health 42: 303-314

Lacasse Y, Martin S, Gagné D, Lakhal L (2009) Dose-response meta-analysis of silica and lung cancer. Cancer Causes Control 20: 925-933
Lehmann F, Hambeck L, Linkert KH, Lutze H, Reiber H, Renner HJ, Reinisch A, Seifert T, Wolf F (1998) Belastung durch ionisierende Strahlung im Uranerzbergbau der ehemaligen DDR. Hauptverband der gewerblichen Berufsgenossenschaften: Sankt Augustin

Mundt K, Kenneth A, Birk T, Parsons W, Borsch-Galetke E, Siegmund K, Heavner K, Guldner K (2011) Respirable crystalline silica exposureresponse evaluation of silicosis morbidity and lung cancer mortality in the German porcelain industry cohort. J Occup Environ Med 53: 282-289

Pelucchi C, Pira E, Piolatto G, Coggiola M, Carta P, La Vecchia L (2006) Occupational silica exposure and lung cancer risk: a review of epidemiological studies 1996-2005. Ann Oncol 17: 1039-1050

Preston DL, Lubin JH, Pierce DA, McConney ME (1998) Epicure, release 2.10. HiroSoft: Seattle

Pukkala E, Guo J, Kyyrönen P, Lindbohm M-L, Sallmén M, Kauppinen T (2005) National job-exposure matrix in analyses of census-based estimates of occupational cancer risk. Scand J Work Environ Health 31: 97-107

Rice FL, Park R, Stayner L, Smith R, Gilbert S, Checkoway H (2001) Crystalline silica exposure and lung cancer mortality in diatomaceous earth industry workers: a quantitative risk assessment. Occup Environ Med 58: 38-45

Schnelzer M, Hammer GP, Kreuzer M, Tschense A, Grosche B (2010) Accounting for smoking in the radon-related lung cancer risk among German uranium miners: results of a nested case-control study. Health Phys 98: 20-28

Soutar C, Robertson A, Miller B, Searl A, Bignon J (2000) Epidemiological evidence on the carcinogenicity of silica: factors in scientific judgement. Ann Occup Hyg 44: 3-14

Steenland K, Brown D (1995) Mortality study of gold miners exposed to silica and nonasbestiform amphibole minerals: an update with 14 more years of follow-up. Am J Ind Med 27: 217-229

Steenland K, Mannetje A, Boffetta P, Stayner L, Attfield M, Chen J, Dosemeci M, DeKlerk N, Hnizdo E, Koskela R, Checkoway H (2001) Pooled exposure-response analysis and risk assessment for lung cancer in 10 cohorts of silica-exposed workers: an IARC multicentre study. Cancer Causes Control 12: 773-784; Erratum: Cancer Causes Control 2002; 13: 777

Taeger D, Krahn U, Wiethege T, Ickstadt K, Johnen G, Eisenmenger A, Wesch H, Pesch B, Brüning T (2008) A study on lung cancer mortality related to radon, quartz, and arsenic exposures in German Uranium Miners. J Toxicol Environ Health 71: 859-865

Ulm K, Waschulzik B, Ehnes H, Guldner K, Thomasson B, Schwebig A, Nuss H (1999) Silica dust and lung cancer in the German stone, quarrying, and ceramics industries: results of a case-control study. Thorax 54: 347-351

Vacek P, Verma D, Graham W, Callas P, Gibbs G (2011) Mortality in Vermont granite workers and its association with silica exposure. Occup Environ Med 68: 312-318

Walsh L (2007) A short review of model selection techniques for radiation epidemiology. Radiat Environ Biophys 46: 205-213

Walsh L, Dufey F, Tschense A, Schnelzer M, Grosche B, Kreuzer M (2010b) Radon and the risk of cancer mortality - internal Poisson models for the German Uranium miners cohort. Health Phys 99: 292-300

Walsh L, Tschense A, Schnelzer M, Dufey F, Grosche B, Kreuzer M (2010a) The influence of radon exposure on lung cancer mortality in German uranium miners, 1946-2003. Radiat Res 173: 79-90

This work is published under the standard license to publish agreement. After 12 months the work will become freely available and the license terms will switch to a Creative Commons Attribution-NonCommercial-Share Alike 3.0 Unported License. 